\title{
How to Decompress the Pressure - The Moderating Effect of IT Flexibility on the Negative Impact of Governmental Pressure on Business Agility
}

\author{
Andreas Reitz \\ Frankfurt School of Finance \& \\ Management \\ a.reitz@fs.de
}

\author{
Christian Jentsch \\ University of Bamberg \\ christian.jentsch@uni- \\ bamberg.de
}

\author{
Daniel Beimborn \\ Frankfurt School of Finance \& \\ Management \\ d.beimborn@fs.de
}

\begin{abstract}
In times of digital transformation banks need to behave agile and increase their speed in IT. At the same time, they are bound by an increasing number of regulatory rules at an increasing pace that force them to act carefully. Since governments frequently introduce new regulatory terms, especially in the finance sector, regulation is a changing phenomenon itself, which forces banks to adjust and change their systems constantly. To manage these challenges, we argue that successful businesses need to have a flexible IT architecture in place. This should enable them to update and reconfigure their systems in a cost effective and prompt manner. By doing this, they should be able to compensate for the regulatory pressure and remain agile.

Based on an analysis of 119 survey results, we find that business agility is indeed lower for higher regulatory pressure and that this effect is mitigated by a flexible IT.
\end{abstract}

\section{Introduction}

In times of digital transformation, organizations in many industries, e.g. healthcare, insurance or banks, more than ever need to behave in an agile manner and increase their speed in IT [1]. The banking industry, in particular, suffering from low interest rates and other phenomena, requires this agility due to the pressure of digital disruptions [2]. Furthermore, due of very similar product structures, banks have to monitor their competitors and react quickly [3]. This forces them to accelerate their innovation cycles and sense and respond to changing environments and customer needs by flexibly adjusting their business processes to the changing environment [4]. At the same time, these industries are bound by a vast number of regulatory rules that force organizations to act carefully. Regulation in this context requires financial service providers to accomplish certain tasks without violating a tremendous number of rules, e.g. data protection (a possible example would be the usage of the same system for two different business units. This could bear the risk that sensitive data gets out of defined regulatory bounds). These rule sets therefore effectively reduce the number of possible ways to solve problems and result in a less agile behavior.

Since governments frequently introduce new regulatory terms especially in the finance sector $[5,6]$, regulation is a changing phenomenon itself, which forces banks to adjust and change their systems constantly. Additionally, the extent of regulatory requirements increases every year (see Figure 1).

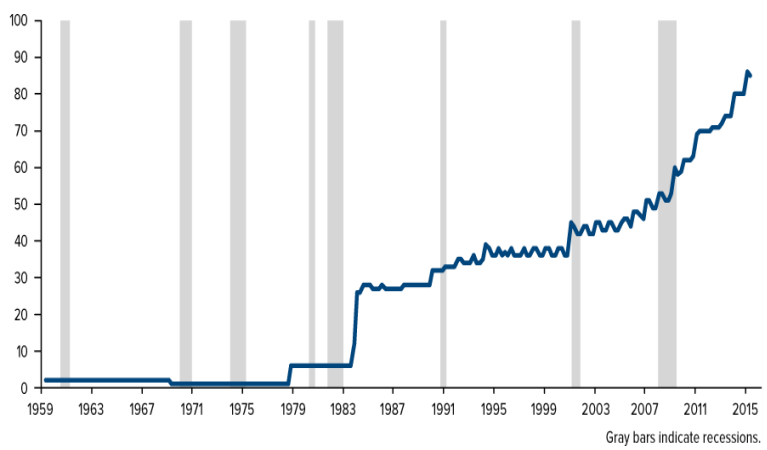

Figure 1: Number of Pages Per Regulatory Filing [7]

Thus, companies in regulated environments like in the finance sector are forced to address the rising number of regulations while competing against new upcoming business models. To manage these challenges, we argue that successful businesses need to have a flexible IT architecture in place to compensate for the regulatory pressure and be agile in a turbulent environment. Being able to quickly, effectively, and cost-efficiently implement new regulatory requirements in their systems and business processes allows these companies slack to head the market with new products and services, i.e., to exhibit strategic agility. Thus, our research question is: 
RQ: Does IT flexibility compensate the negative impact of regulatory pressure on a firm's market agility?

To test our hypotheses, we collected data in the banking industry in Germany, Austria, and Switzerland using a survey-based approach.

This paper is structured as follows: First, we introduce the constructs of business agility, IT flexibility, and regulatory pressure. Based on those, we develop the research model and derive our hypotheses. We then describe the research methodology, present our findings, and discuss their implications. We close with concluding remarks of our work and ideas for further research.

\section{Theoretical Background}

Since many studies in MIS research do not make a distinction between agility and flexibility, we start with a brief description of both before continuing with the model development.

\subsection{Business Agility}

Evolvement and conceptualization of business agility in previous research has been done using resource-based [8, 9] and/or dynamic capability arguments $[1,4,10]$. Business agility is a dynamic capability which helps the firm to flexibly deploy organizational resources in responding to environmental changes. A present explanation for the need of organizational agility is environmental dynamism which may negatively impact firms' performance [1, 9]. To address environmental dynamism firms need to continually sense and respond to emerging environmental changes [4]. Thus, agility has been frequently described, for example by Chen, et al. [9], as an organizational capability "that can help firms to better acquire and deploy resources to match a firm's market environment." (p.329). Sambamurthy, et al. [11] categorize these environmental changes which need to be sensed and responded to into the three dimensions of agility: customer agility (sensing and responding to customers' needs to quickly identify emerging opportunities), partnering agility (learning from partners to increase speed to market), and operational agility (redesigning processes to increase speed and efficiency). In our paper, in which we focus on the impact of regulatory pressure, we focus particularly on operational agility, by analyzing the agility of the firms' business processes as a response to emerging regulations. Based on Chen, et al. [9] we argue that "with business process agility, firms can rapidly and flexibly redesign existing processes or create new ones to cope with dynamic market conditions." (p. 329).

\subsection{IT Flexibility}

While technical IT infrastructure flexibility (which we refer to from now on as IT flexibility) is one of the main influencing factors of a firm's speed to act/respond [12], it is an antecedent of business agility [13]. Nevertheless, IT flexibility includes other factors and aspects that do not affect speed. Even if a company's IT is inflexible, it might be able to rearrange and reconfigure itself with a high speed, but at a great cost. Therefore, agility and flexibility are two different concepts. Agility is about the speed to detect opportunities and to react to them in the business context while flexibility is about malleability of the system and the ability to respond quickly and economically. Therefore, a flexible IT has emerged as a key competitive advantage in [14] and an important strategic goal [15] that can potentially influence a firm's ability to use and reconfigure IT [14, 16, 17].

Following Byrd and Turner [18], the flexibility of an IT infrastructure consists of the ensemble of technical IT and human infrastructure. Duncan [19] advances this through three criteria for flexibility: (1) connectivity, allowing different components to interact with others through interfaces; (2) compatibility, which facilitates interaction and information exchange between connected components; and (3) modularity, which should reduce dependencies between systems and result in the highest possible standardization [19]. The ability to add, modify or remove any system of the infrastructure with no overall effect [18] should enable greater agility in the optimal configuration [20]. Byrd and Turner have also shown that connectivity and compatibility cannot empirically be separated. They therefore combine them to the dimension of integration, which we follow in our model. Based on those previous works, we conceptualize technical IT flexibility by the two dimensions of modularity and integration of the IT systems.

IT flexibility has also been linked to increased levels of strategic alignment under circumstances that require agile and swift responses by the firm [8]. This demonstrates that a flexible IT infrastructure can facilitate a timely response in terms of IT-based competitive actions, geared towards sustained competitive advantage [21]. In this respect, the IT infrastructure is not only used to support current operations, but is developed on the basis of constant adaptations, or as referred to, a platform for digital options [21]. 


\section{Research Model}

In the next stage, we develop our research model to determine the influence of governmental regulation on business agility in highly regulated companies. We also investigate the moderating effect of IT flexibility. The corresponding structural model is illustrated in Figure 2.

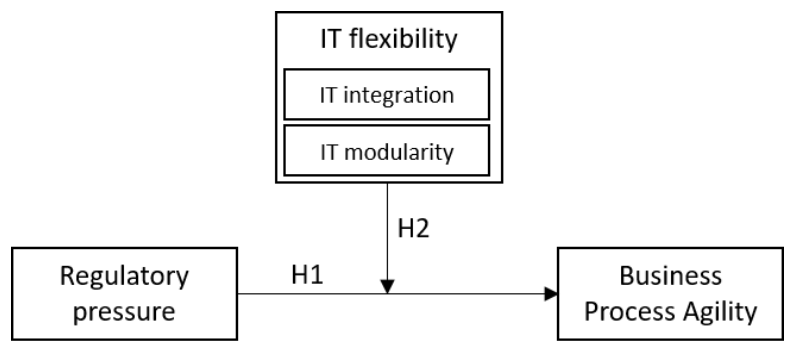

Figure 2. Moderating Effect

Regulatory pressure can occur in two different forms: firstly, when governmental agencies force firms to change the way they work or to include new steps directly or indirectly; and secondly, if they force firms to standardize by providing a reference process. This introduces pressure to change and the uncertainty of whether changes fulfill the requirements. In addition to the pressure it puts on the business side, it is also known to influence the adoption of information systems [22]. These various regulations often affect IS of companies as well IS [22, 23]. As an example, during the introduction of the Sarbanes-Oxley Act (SOX) in 2007 companies discovered that in most cases they did not have the appropriate IS to address the compliance levels of SOX [24], due to e.g. low security standards or lack of monitoring systems. This problem arose in addition to the changes that had to be made to the business processes. Thus, regulatory pressure effectively slowed down the behavior of companies and made them less agile.

\subsection{Effects of pressure on agile behavior}

To characterize the effects of regulatory pressure on business agility, we use institutional theory as a lens. As opposed to other organizational behavior (like transaction cost economics [25] or resource based view [26]), in this context, organizational and behavioral changes mainly arise from the need of legitimacy [27]. According to DiMaggio and Powell [28], there are three different forces: regulatory/coercive, normative, and cognitive/mimetic. We focus on coercive pressure, since normative and mimetic forces do not deal with pressure from regulation.
Coercive pressure arises from government regulations and policies as well as from competitive necessity within the industry [29]. Regulatory forces require changes while simultaneously establish boundaries that effectively reduce the number of ways to realize those changes. For example, using the same system for two different business units could bear risks, as sensitive data could get out of the bounds defined by regulation.

Additionally, regulators usually expect a high level of service quality, which rules out a lot of agile principles (e.g. iterative development, which could leave out a not fundamental part of the developed artefact but is required by regulation). This further slows down the possible reaction to a changed business need and/or regulatory requirement. Regulations do not only affect the way some task is accomplished, but also the schedule. For example, government regulations influence the schedule of adoption projects. Most government regulations define compulsory due dates by which compliance must be achieved. As a result, firms are forced to bring forward adoption projects that were planned for a later time, stall projects that are, at least in terms of regulatory requirements, not required yet, or even initiate unplanned adoption projects [30]. We therefore postulate our first hypothesis:

Hypothesis 1: High regulatory pressure lowers business agility

\subsection{IT flexibility as a decompressor}

Companies that are bound by regulation have fewer options to react to changing requirements and are forced to follow rules that limit their schedule. The question that arises now is whether companies can mitigate this effect by using their flexible IT "to add, modify, and remove any software, hardware, or data components of the infrastructure with ease and with no major overall effect" ([18], p.171).

To build a flexible IT infrastructure concepts such as modularity and integration play a critical role. In case of a regulatory change, the business process needs to be adjusted and likewise the IT infrastructure to support the respective business process. If this IT system is modular, the modules that need to be changed can be easily isolated, the impact of the change to the IT system can be limited, and the company can react in a swift manner. In some cases, a simple rearrangement and reconfiguration of the modules might be sufficient. As an example, in a bank's credit granting process, there might be the requirement that the applicants' financial background needs to be checked in a different way (e.g. using fewer factors for scoring). If it is possible to use that 
module from a different IT system and easily integrate it, the bank can quickly react and run business as usual.

Due to regulations, it might be necessary to stop a project in a premature state. This might be less of a problem if the project is modular, because then only the work done on the last module is lost. Therefore it might become easier to continue the project in a later point in time [31].

Summing up, we posit our second hypotheses:

Hypothesis 2: A flexible IT reduces the negative effect of high regulatory pressure

\section{Research Methodology}

To test our hypotheses, we applied a survey-based research approach. In 2016, we conducted a survey with participants from the banking industry in Germany, Austria, and Switzerland. We chose this industry as it is put under a lot of pressure through a high-level of regulation. We focused on two core business processes of these banks, namely the process of granting/managing private real estate loans and the process of granting/managing loans for investments of small and medium-sized enterprises (SMEs). The two processes were chosen, as a firm level measurement would diffuse the net effect because of the variation between too different and diverse organizational areas. The choice to only look into a single industry reduces further contingency effects, as suggested by Chiasson and Davidson [32].

As a first step, we selected the 1000 largest banks in Germany, Austria, and the German-speaking part of Switzerland. We contacted each bank individually by telephone and tried to identify the two managers responsible for the two credit handling processes mentioned above. As a result, we could contact 1868 senior managers by phone. If the manager agreed to participate, we sent out the questionnaire and instigated a reminder by telephone after 10 days and by e-mail after 20 days. Managers who did not reply after 20 days were contacted again. This process resulted in a total of 202 completed questionnaires (which corresponds to a response rate of $10.8 \%$ ). After dropping questionnaires with missing answers, we ran our subsequent model tests based on 119 responses ${ }^{1}$.

\footnotetext{
${ }^{1}$ This case-wise deletion approach is the most conservative approach. We also ran the model with the full data set $(n=202)$ after replacing missing values, but did not find structurally different results.
}

\subsection{Survey Design}

The survey was designed by three researchers with the help of one consultant from the banking industry. It was refined in three additional iterations using the help of three additional consultants from the banking industry. Concluding the design, we tested the final survey with three banking managers. The questionnaire starts with a brief introduction which provides guidance for the respondent. In addition, we visualized and described the business processes (credit handling processes) we were analyzing in this survey.

\subsection{Measurement Development}

To develop the survey, we first analyzed the existing literature on IT flexibility, business process agility, and regulatory pressure. Besides regulatory pressure, appropriate measurement instruments existed for all constructs and we therefore could adopt most items from previous empirical studies. The constructs were operationalized using reflective multi-item measures. Slight adaptations, based on the insights from pre-tests and interviews, were made to the items to reflect the banking domain as the research context.

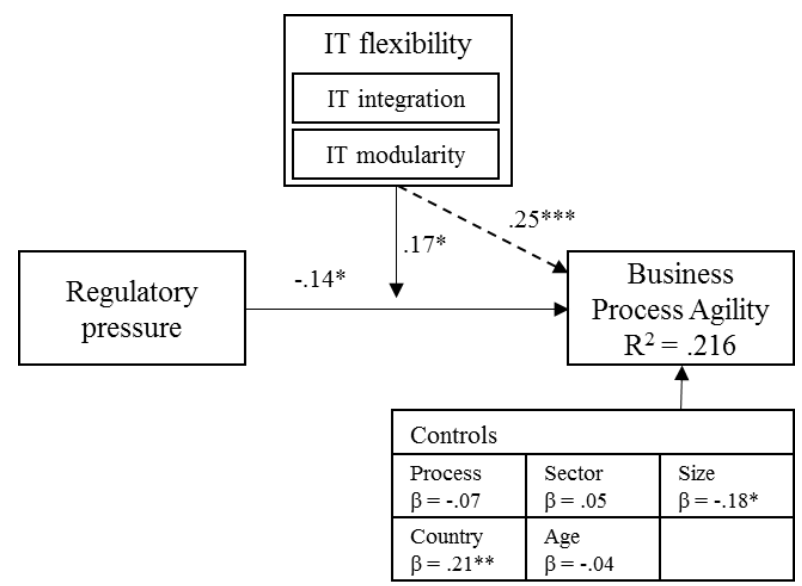

Figure 3. Estimation Results

Notes: $\mathrm{N}=131 . * * * \mathrm{p}<0.001 ; * * \mathrm{p}<0.01 ; * \mathrm{p}<0.05$

The measurements for IT modularity were adapted from the items from Tanriverdi, et al. [33]. Items measuring integration were self-developed based on the logic of IT integration in Ross' seminal article on IT architecture maturity [34]. We developed the items for business agility based on the work of Tallon and Pinsonneault [8]. The items measuring regulatory pressure were self-developed with the help of the external consultants. All items were measured using a 5 -point Likert scale. Table 1 in the appendix lists all 
items and respective scales we applied in the survey instrument to elaborate our research model.

As controls we used process type (type of credit), country, size (based on balance sheet total), bank sector (commercial banks, cooperatives or public savings banks), and work experience (in years) of the respondent (see Figure 3). We applied 17 items to validate our research model.

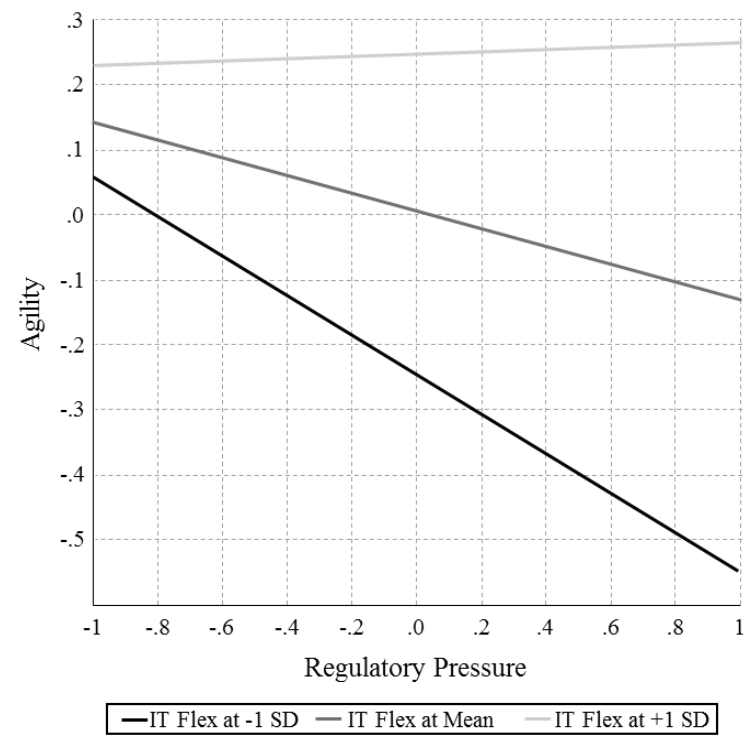

Figure 4. Moderating Effect

\section{Results}

To test our model, we used PLS and applied the smartPLS 3 software package. Before we tested the actual research model, we checked the quality and reliability of our data and measures.

Due to our data collection approach in which we sent out up to three reminders, we need to make sure that our data does not suffer from non-response bias (NRB). As suggested by Armstrong and Overton [35] individuals who respond after one or two reminders share properties with individuals who do not reply at all. In our analysis, no indicator showed a significant difference and we can therefore conclude that nonresponse bias is not a major problem.

Furthermore, we searched for indications of the negative impact of a common method bias (CMB). We applied two techniques to search for indications of CMB. First, we used the Harman single-factor test. This technique did not reveal any component explaining the majority of overall variance (the largest component explained $36.5 \%$ ). In addition, we included a theoretically unrelated variable ("The competition in our loans market is very strong.") in our model that was linked to each construct of the original model. The results did not reveal structural differences in levels and significance of path coefficients or in the level of $\mathrm{R}^{2}$ of the dependent variables.

Finally, we focused on construct validity and reliability. The results are highlighted in Table 2 in the appendix. The composite reliability values are above .8 , the average variances extracted are far above .5 and the discriminant statistics show that the inter-construct correlations are always lower than the square root of the respective construct's AVE. Summarizing, we can assume that our measures and our data fulfill the necessary statistical criteria with regard to reliability and validity and thus allow for testing the developed research model.

The results from testing our model by using PLS are highlighted in Figure 3. They show a strong and significant 2 negative relationship of -.14 between regulatory pressure and business process agility. We therefore find support for Hypothesis 1. Furthermore, we find a significant influence of .017 of IT flexibility on this relationship as well as a strong positive influence of 0.25 of IT flexibility on business process agility. This supports Hypothesis 2 .

The moderating effect of IT flexibility on the relationship between regulatory pressure and IT agility is visualized in Figure 4. Supporting Hypothesis 1, we find that regulatory pressure (without IT flexibility as a moderating factor) has an enormous impact on IT agility (see black line: IT Flex at -1 SD). Interestingly, it can be seen that IT flexibility can substantially reduce the negative impact of regulatory pressure on IT agility, which supports Hypothesis 2.

\section{Implications, Conclusion, Limitations and Further Research}

Our empirical findings show that high regulatory pressure negatively impacts the level of business process agility. Thus, industries which are confronted with a substantial number and a high frequency of governmental regulations become inflexible in realizing changes necessary for business. This is because they tend to organize their business processes to address the regulations (H1 supported).

In contrast, firms that succeed to organize their IT in a flexible way can reduce this negative effect between regulatory pressure and business process agility. This implies that if a certain regulation requires a change of a business process, the company can act in a relatively quick and economic way. A company can achieve this by rearranging and modifying the supporting IT systems (H2 fully supported).

\footnotetext{
${ }^{2}$ Significance tests were run based on data from 2000 bootstrap runs.
} 
Our research is interesting because it covers the problems that arise from regulatory pressure in IS. Still, there is little understanding of how regulation really affects agile behavior of companies. This is of special importance since a lot of IT systems in different industries are a potential target for regulation.

These insights should also be valuable to practitioners. Since regulation requires banks to constantly change, a flexible IT could reduce that impact and get independent. This could enable banks to be proactive in gaining competitive advantages instead of reacting to required changes. Since our collected data is from a highly regulated industry, our findings should be transferable to other regulated industry sectors, like health-care or insurance.

A potentially limiting factor is our focus on process managers as respondents. Additionally, we did not capture the perceptions of the IT unit. Despite this, we argue that process managers are the appropriate respondents, as they can answer if they are bound by regulatory pressure. Furthermore, they can perceive whether their IT can support them in a flexible way. The argument of reversed causality can be excluded, because it is highly unlikely that agile acting firms are being highly pressured by regulation.

After analyzing all 119 survey results, we can summarize, that high regulatory pressure prevents firms from acting agilely. Nevertheless, this inhibitor can be addressed by a flexible IT.

\section{References}

[1] A. Chakravarty, R. Grewal, and V. Sambamurthy, "Information Technology Competencies, Organizational Agility, and Firm Performance: Enabling and Facilitating Roles," Information Systems Research, vol. 24, no. 4, pp. 976-997, 2013.

[2] R. Baskerville, M. Cavallari, K. Hjort-Madsen, J. Pries-Heje, M. Sorrentino, and F. Virili, "The strategic value of SOA: a comparative case study in the banking sector," International Journal of Information Technology and Management vol. 9, no. 1, pp. 30-53, 2010.

[3] S. Wright, E. R. Eid, and C. S. Fleisher, "Competitive Intelligence in Practice: Empirical Evidence from the UK Retail Banking Sector," Journal of Marketing Management, vol. 25, no. 910, pp. 941-964, 2009.

[4] O.-K. D. Lee, V. Sambamurthy, K. H. Lim, and K. K. Wei, "How Does IT Ambidexterity Impact Organizational Agility?," Information Systems Research, vol. 26, no. 2, pp. 398-417, 2015.

[5] T. Fiennes. (2013, 11/06/2017). Regulation and the Financial System. Available: http://www.usfunds.com/investor-library/franktalk/trump-were-getting-railed-by-high-taxes-andregulations/\#.WT-xJGjyhaR
[6] F. Holmes. (2016, 13/06/2017). Trump: We're Getting Railed by High Taxes and Regulations. Available: http://www.usfunds.com/investorlibrary/frank-talk/trump-were-getting-railed-byhigh-taxes-and-regulations/\#.WT-xJGjyhaR

[7] T. O. Goup, TOGAF Version 9, 9 ed. (TOGAF series). Zaltbommel: Van Haren Publishing, 2009, p. 744.

[8] P. P. Tallon and A. Pinsonneault, "Competing Perspectives on the Link Between Strategic Information Technology Alignment and Organizational Agility: Insights from a Mediation Model " MIS Quarterly, vol. 35, no. 2, pp. 463486, 2011.

[9] Y. Chen, Y. Wang, S. Nevo, J. Jin, L. Wang, and W. S. Chow, "IT capability and organizational performance: the roles of business process agility and environmental factors," European Journal of Information Systems, vol. 23, pp. 326-342, 2014.

[10] N. Roberts and V. Grover, "Leveraging Information Technology Infrastructure to Facilitate a Firm's Customer Agility and Competitive Activity: An Empirical Investigation," Journal of Management Information Systems, vol. 28, no. 4, pp. 231-269, 2012.

[11] V. Sambamurthy, A. Bharadwaj, and V. Grover, "Shaping Agility through Digital Options: Reconceptualizing the Role of Information Technology in Contemporary Firms," MIS Quarterly, vol. 27, no. 2, pp. 237-263, 2003.

[12] A. Tiwana and B. Konsynski, "Complementarities Between Organizational IT Architecture and Governance Structure," Info. Sys. Research, vol. 21, no. 2, pp. 288-304, 2010.

[13] P. M. Swafford, S. Ghosh, and N. Murthy, "The antecedents of supply chain agility of a firm: Scale development and model testing," Journal of Operations Management, vol. 24, no. 2, pp. 170188, 2006/01/01/ 2006.

[14] G. Ray, W. A. Muhanna, and J. B. Barney, "Information Technology and the Performance of the Customer Service Process: A Resource-based Analysis," MIS Quarterly, vol. 29, no. 4, pp. 625652, 2005.

[15] R. L. Kumar, "A framework for assessing the business value of information technology infrastructures," Journal of Management Information Systems, vol. 21, no. 2, pp. 11-32, 20042004.

[16] A. S. Bharadwaj, "A Resource-Based Perspective on Information Technology Capability and Firm Performance: An Empirical Investigation," MIS Quarterly, vol. 24, no. 1, pp. 169-196, 2000.

[17] G. D. Bhatt and V. Grover, "Types of Information Technology Capabilities and Their Role in Competitive Advantage: An Empirical Study," Journal of Management Information Systems, vol. 22, no. 2, pp. 253-277, 2005.

[18] T. A. Byrd and D. E. Turner, "Measuring the flexibility of information technology infrastructure: Exploratory analysis of a construct," Journal of 
Management Information Systems vol. 17, no. 1 pp. 167-208, 2000.

[19] N. B. Duncan, "Capturing flexibility of information technology infrastructure: A study of resource characteristics and their measure," Journal of Management Information Systems, vol. 12, no. 2, pp. 37-57, 1995.

[20] M. A. Schilling, "Toward a general modular systems theory and its application to interfirm product modularity," Academy of Management Review, vol. 25, no. 2, pp. 312-334, 20002000.

[21] E. Overby, A. Bharadwaj, and V. Sambamurthy, "Enterprise agility and the enabling role of information technology.," European Journal of Information Systems, vol. 15, no. 120-131, 2006.

[22] K. Krell, S. Matook, and F. Rohde, "The effects of regulatory pressure on information system adoption success: An institutional theory perspective," in ECIS, 2009, pp. 1295-1305.

[23] A. Braganza and A. Franken, "SOX, compliance, and power relationships," Communications of the ACM, vol. 50, no. 9, pp. 97-102, 2007.

[24] J. C. Sipior and B. T. Ward, "Unintended invitation: organizational wi-fi use by external roaming users," Commun. ACM, vol. 50, no. 8, pp. 72-77, 2007.

[25] O. E. Williamson, "The economics of organization: The transaction cost approach," American journal of sociology, vol. 87, no. 3, pp. 548-577, 1981.

[26] D. J. Teece, G. Pisano, and A. Shuen, "Dynamic capabilities and strategic management," Strategic management journal, pp. 509-533, 1997.

[27] J. W. Meyer and B. Rowan, "Institutionalized organizations: Formal structure as myth and ceremony," American journal of sociology, vol. 83, no. 2, pp. 340-363, 1977.

[28] P. J. DiMaggio and W. W. Powell, "The Iron Cage Revisited: Institutional Isomorphism and Collective Rationality in Organizational Fields " American Sociological Review, vol. 48, no. 2, pp. 147-160, 1983.

[29] I. Guler, M. F. Guillen, and J. M. Macpherson, "Global Competition, Institutions, and the Diffusion of Organizational Practices: The International Spread of ISO 9000 Quality Certificates," Administrative Science Quarterly, vol. 47, no. 2, pp. 207-232, 2002.

[30] V. Garcia, "Seven points financial services institutions should know about IT spending for compliance," Journal of Financial Regulation and Compliance, vol. 12, no. 4, pp. 330-339, 2004.

[31] H. A. Simon, "The Architecture of Complexity," Proceedings of the American Philosophical Society, vol. 106, no. 6, pp. 467-482, 1962.

[32] M. W. Chiasson and E. Davidson, "Taking industry seriously in information systems research," Mis Quarterly, pp. 591-605, 20052005.

[33] H. Tanriverdi, P. Konana, and L. Ge, "The Choice of Sourcing Mechanisms for Business Processes," Info. Sys. Research, vol. 18, no. 3, pp. 280-299, 2007/09// 2007.
[34] J. Ross, W, "Creating a Strategic IT Architecture Competency: Learning in Stages," MIS Quarterly, vol. 2, no. 1, pp. 31-43, 2003.

[35] J. S. Armstrong and T. S. Overton, "Estimating nonresponse bias in mail surveys," Journal of marketing research, vol. 14, no. 3, pp. 396-402, 1977. 


\section{Appendix}

\begin{tabular}{|c|c|c|c|c|}
\hline ID & $\begin{array}{l}\text { Loading } \\
\text { (all } \\
\text { signif. at } \\
\mathrm{p}<.001 \text { ) }\end{array}$ & Item & Scale & Source \\
\hline \multicolumn{5}{|l|}{ Agility } \\
\hline Agill & .879 & $\begin{array}{l}\text { We can adapt our process agile (fast, cheap, consistent) } \\
\text { to changed business requirements. }\end{array}$ & \multirow{3}{*}{$\begin{array}{l}\text { 5-point } \\
\text { Likert scale } \\
\text { (Range: } \\
\text { "Completely } \\
\text { disagree" to } \\
\text { "Completely } \\
\text { agree" }\end{array}$} & \multirow{3}{*}{$\begin{array}{lr}\text { Adapted from } \\
\text { Tallon and } \\
\text { Pinsonneault [8] }\end{array}$} \\
\hline Agil2 & .914 & $\begin{array}{l}\text { We can quickly adapt our process to a changed } \\
\text { environment. }\end{array}$ & & \\
\hline Agil3 & .903 & $\begin{array}{l}\text { In case of changes in customer demands, we can } \\
\text { respond quickly and effectively. }\end{array}$ & & \\
\hline \multicolumn{5}{|c|}{ Regulatory pressure } \\
\hline Pres1 & .672 & $\begin{array}{l}\text { The number of regulatory requirements and audits is } \\
\text { enormous. }\end{array}$ & \multirow{3}{*}{$\begin{array}{l}\text { 5-point } \\
\text { Likert scale } \\
\text { (Range: } \\
\text { "Completely } \\
\text { disagree" to } \\
\text { "Completely } \\
\text { agree" }\end{array}$} & \multirow[t]{3}{*}{ Self-developed } \\
\hline Pres2 & .923 & Regulation introduces uncertainty to a lot of tasks. & & \\
\hline Pres3 & .734 & $\begin{array}{l}\text { Our organization is overwhelmed by the vast number of } \\
\text { regulatory requirements. }\end{array}$ & & \\
\hline \multicolumn{5}{|c|}{ IT modularity } \\
\hline ITMod1 & .837 & $\begin{array}{l}\text { The processes are well reflected in the modular of the } \\
\text { IT system. }\end{array}$ & \multirow{3}{*}{$\begin{array}{l}\text { 5-point } \\
\text { Likert scale } \\
\text { (Range: } \\
\text { "Completely } \\
\text { disagree" to } \\
\text { "Completely } \\
\text { agree" }\end{array}$} & \multirow{3}{*}{$\begin{array}{l}\text { Adapted from } \\
\text { Tanriverdi, et al. } \\
\text { [33] }\end{array}$} \\
\hline ITMod2 & .886 & $\begin{array}{l}\text { Structure of the process and IT system were } \\
\text { coordinated. }\end{array}$ & & \\
\hline ITMod3 & .873 & $\begin{array}{l}\text { Design of the process and IT system were designed } \\
\text { using a common reference model. }\end{array}$ & & \\
\hline \multicolumn{5}{|c|}{ IT integration } \\
\hline ITInt1 & .753 & $\begin{array}{l}\text { All sub-processes of our process use the same } \\
\text { underlying database. }\end{array}$ & \multirow{3}{*}{$\begin{array}{l}\text { 5-point } \\
\text { Likert scale } \\
\text { (Range: } \\
\text { "Completely } \\
\text { disagree" to } \\
\text { "Completely } \\
\text { agree" }\end{array}$} & \multirow{3}{*}{$\begin{array}{l}\text { Self-developed, } \\
\text { based on Ross } \\
{[34]}\end{array}$} \\
\hline ITInt2 & .824 & $\begin{array}{l}\text { Data handled and maintained in our business unit is } \\
\text { being used by other business units. }\end{array}$ & & \\
\hline ITInt3 & .916 & All business units use the same underlying database. & & \\
\hline
\end{tabular}

Table 1. Survey items

\begin{tabular}{|l|c|c|c|c|c|c|c|}
\hline \multirow{2}{*}{ Construct } & \multirow{2}{*}{ C.R. } & \multirow{2}{*}{ AVE } & \multicolumn{6}{|c|}{$\begin{array}{c}\text { Discriminant statistics (inter-construct correlations } \\
\text { and square root of AVE in shaded cells) }\end{array}$} \\
\cline { 4 - 9 } & & & $\# 1$ & $\# 2$ & $\# 3$ & $\# 4$ & $\# 5$ \\
\hline Agility (\#1) & .926 & .808 & .899 & & & & \\
\hline Regulatory Pressure (\#2) & .824 & .614 & -.148 & .784 & & & \\
\hline IT flexibility - modularity (\#3) & .899 & .749 & .382 & .001 & .865 & & \\
\hline IT flexibility - integration (\#4) & .871 & .695 & .086 & -.019 & .450 & .833 & \\
\hline Moderating Effect (\#5) & .742 & .238 & .188 & .000 & .000 & .000 & .488 \\
\hline
\end{tabular}

Table 2. Construct based quality criteria 